\section{Chronic Wasting Disease}

Last Updated: July 2016

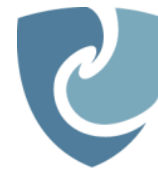

The Center for Food Security \& Public Health

INSTITUTE FOR INTERNATIONAL COOPERATION IN ANIMAL BIOLOGICS

\section{IOWA STATE UNIVERSITY} College of Veterinary Medicine

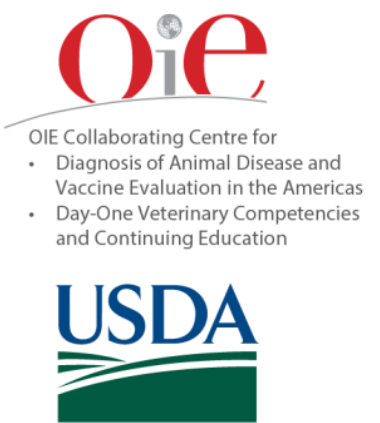

www.cfsph.iastate.edu

Email: cfsph@iastate.edu

\section{Importance}

Chronic wasting disease (CWD) is a neurodegenerative disease caused by a prion that affects cervids including deer, elk and moose. At one time, CWD was an obscure illness that seemed to occur only in a small geographic area in northeastern Colorado and southeastern Wyoming. However, this disease is now found in wild and/or farmed cervids in many other states in the U.S., where it appears to be slowly spreading, and in parts of Canada. South Korea reported outbreaks among captive cervids between 2004 and 2010, after importing infected animals from Canada, and Norway detected CWD in wild cervids in 2016.

Chronic wasting disease can be devastating in farmed herds. This disease is always fatal once the clinical signs appear, and most or all of the herd can eventually become infected. It is one of the most difficult prion diseases to control: CWD prions are transmitted from animal to animal, and they can also be spread from contaminated environments for up to two years or more. Thousands of captive or wild deer and elk have been killed in the U.S. and Canada in control efforts. In addition, there are concerns about any potential for CWD to affect other species, including humans. Cooking does not destroy prions, and ingestion of another prion, the agent that causes bovine spongiform encephalopathy (BSE), has been linked to a fatal human neurological disease. CWD prions have been found in muscle (meat), as well as other tissues of cervids, and could enter the food supply. The evidence so far suggests that CWD does not affect humans, livestock or wild predators of cervids; nevertheless, the possibility that it could be zoonotic has not been ruled out.

\section{Etiology}

CWD is a member of the transmissible spongiform encephalopathies (TSEs), a group of neurodegenerative disorders caused by prions. Prions are infectious proteins that appear to replicate by converting a normal cellular protein into copies of the prion. The cellular protein, which is called PrPc, is found on the surface of neurons. Pathogenic isoforms of PrPc are designated PrPres; $\mathrm{PrP}^{\mathrm{CWD}}$ or PrP ${ }^{\mathrm{TSE}}$ are other names for this protein. There may be more than one variant of the CWD prion.

\section{Species Affected}

Chronic wasting disease is known to affect a number of cervid species. Naturally acquired cases have been reported in mule deer (Odocoileus hemionus), black-tailed deer (O. hemionus columbianus), white-tailed deer (O. virginianus), Rocky Mountain elk (Cervus elaphus nelsoni), captive red deer (Cervus elaphus elaphus), moose (Alces alces) and wild reindeer (Rangifer tarandus tarandus). There are unpublished reports of infections in captive sika deer (Cervus nippon), and crosses of sika and red deer, from South Korea. Caribou, which are subspecies of $R$. tarandus (e.g. Rangifer tarandus caribou, Rangifer tarandus granti), are also likely to be susceptible. Reeve's muntjac deer (Muntiacus reevesi) have been infected by oral inoculation in the laboratory; however, fallow deer (Cervus dama dama) might be relatively resistant to CWD. Although prions replicated in the latter species after intracerebral inoculation, prion deposition in the brain was sparse, and no fallow deer became infected after 6 or more years of exposure to infected deer and contaminated pastures.

There is currently no evidence that CWD prions have infected any animals other than cervids in nature. Of the species infected experimentally to date, only squirrel monkeys (Saimiri sciureus) became infected after oral inoculation. Cynomolgus macaques (Macaca fascicularis) injected either intracebrally or orally had no evidence of infection. Some other mammals, including cattle, sheep, goats, ferrets, mink, cats and several North American or European rodents, were susceptible to direct intracerebral inoculation of CWD prions, a method that bypasses normal species barriers. However, attempts to infect cattle, cats, ferrets or mink by feeding prions from cervids have failed. Epidemiological studies also suggest that cattle are unlikely to be susceptible: chronic wasting disease has not been reported in any cattle co-pastured with deer or elk, or in surveys of cattle in endemic areas. Oral challenge studies have not been published for sheep and goats, but some molecular studies suggest that the species barriers to CWD prion replication might be lower in sheep 


\section{Chronic Wasting Disease}

than cattle. Studies to date have found no evidence of CWD infections in wild scavengers including coyotes (Canis latrans), mink (Mustela vison), opossums (Didelphis virginiana), raccoons (Procyon lotor) and other species in endemic areas. Raccoons inoculated intracerebrally had no evidence of prion replication. CWD prions do not replicate readily in most laboratory rodents (including wild type mice), although hamsters are susceptible to intracerebral inoculation to a limited degree.

\section{Zoonotic potential}

As of 2016, surveillance, investigation of suspicious cases of neurological disease in humans and epidemiological studies have found no evidence that chronic wasting disease is zoonotic. Experimental infections in squirrel monkeys have raised some concerns; however, the inability of CWD prions to infect cynomolgus macaques, a primate more closely related to humans, may be reassuring. Molecular compatibility studies suggest that there is a significant species barrier and the CWD prion is not well adapted to infect humans. Nevertheless, the possibility that CWD is zoonotic cannot be ruled out at this time.

\section{Geographic Distribution}

Chronic wasting disease was originally reported only from a limited area of the U.S. encompassing northeastern Colorado, southwestern Nebraska, and southeastern Wyoming, but it has now spread extensively in North America. As of 2016, this disease has been found in wild and/or captive cervid populations extending from the original focus east as far as Maryland, Pennsylvania and Virginia, north to Wisconsin and South Dakota, and in Utah, New Mexico and Texas. Its distribution is, however, patchy, and some states within this area have not reported infections. Two Canadian provinces, Alberta and Saskatchewan, are also affected. Some states with only limited outbreaks in wild cervids (e.g., New York) are thought to have eradicated CWD; however, the presence of infected wild cervids in neighboring states may make their ongoing status uncertain.

In the Republic of Korea, chronic wasting disease was reported in imported deer and elk in 2001, in the offspring of imported elk in 2004, and in captive red deer, sika deer, and crosses of these species in 2010. As of 2016, no infections have been reported in indigenous cervids in Korea. In 2016, CWD was first documented in wild cervids (reindeer and moose) in Norway. The source of the latter outbreak is currently unknown.

\section{Transmission}

Chronic wasting disease seems to spread horizontally between cervids by direct contact, environmental contamination or a combination of these routes. CWD prions have been transmitted experimentally between deer by the oral and intranasal routes, in aerosols and by blood transfusion. Grazing is thought to be important in acquiring these prions from the environment. In deer, prions have been detected in saliva, blood, urine, feces and antler velvet, and some sources (e.g., saliva, feces, urine) can contain these agents before the animal develops clinical signs. While the concentration of prions in urine and feces is very low, the volume of these excretions could contribute significantly to environmental contamination over the course of the infection. Elk, which have smaller amounts of prions in lymphoid tissues than deer, are thought to transmit CWD less efficiently. Nevertheless, these agents have been found in some secretions and excretions of elk, including feces. Prions have also been detected in the skeletal muscles and fat of deer, and in heart muscle from white-tailed deer, elk and experimentally infected red deer. The occurrence of prions in blood and lymphoid tissues suggests that no tissues from infected cervids should be considered prionfree. Vertical transmission has, to date, been documented in the offspring of wild elk, as well as in experimentally infected Reeves' muntjac deer. Whether CWD prions can be shed in milk is unknown.

CWD prions can be transmitted on contaminated fomites, even from animals not yet displaying clinical signs, and seem to persist for a few years in the environment. Cases have been reported after exposure to infected carcasses left to decompose in pastures approximately two years earlier. Infectivity was also reported on pastures more than two years after infected deer were removed. CWD prions can remain infectious after passage through the digestive tracts of scavengers or predators that may feed on deer; this has been demonstrated in the laboratory for coyotes and crows. Prions can bind to soils, and soil-bound prions are infectious for cervids. Their persistence differs between soil types. Repeated cycles of wetting and drying soil in the laboratory are reported to decrease, though not necessarily eliminate, infectivity. Although there is at least one report that CWD prions have been found in environmental water, this report needs to be confirmed, and the concentrations appeared to be very low.

\section{Disinfection}

Complete decontamination of prion-contaminated tissues, surfaces and environments can be difficult. These agents are very resistant to most disinfectants, including formalin and alcohol. They are also resistant to heat, ultraviolet radiation, microwave irradiation and ionizing radiation, particularly when they are protected in organic material or preserved with aldehyde fixatives, or when the prion titer is high. Prions can bind tightly to some surfaces, including stainless steel and plastic, without losing infectivity. Prions bound to metal seem to be highly resistant to decontamination.

Relatively few prion decontamination techniques have been published and confirmed to be effective for routine use. Some laboratories pre-treat tissues with formic acid to decrease infectivity before sectioning tissue blocks. 


\section{Chronic Wasting Disease}

A 1-2 $\mathrm{N}$ sodium hydroxide solution, or a sodium hypochlorite solution containing at least $2 \%(20,000 \mathrm{ppm})$ available chlorine, has traditionally been recommended for equipment and surfaces. Surfaces should be treated for more than 1 hour at $20^{\circ} \mathrm{C}\left(68^{\circ} \mathrm{F}\right)$. Overnight disinfection is recommended for equipment. Cleaning before disinfection removes organic material that may protect prions. Experimentally, some milder treatments have also been effective against certain prions, under some conditions. They include a specific phenolic disinfectant, various alkaline and enzymatic detergents (although the efficacy of specific agents within these classes varies), hydrogen peroxide gas plasma, radiofrequency gas plasma, and sodium dodecyl sulfate plus acetic acid. These agents might be useful for items that cannot withstand harsher decontamination procedures. They have mainly been tested against prions other than CWD.

Physical inactivation of prions can be carried out by porous load autoclaving at $134^{\circ} \mathrm{C}\left(273^{\circ} \mathrm{F}\right)$ for 18 minutes at $30 \mathrm{lb} / \mathrm{in}^{2}$. Some reviews also recommend $132^{\circ} \mathrm{C}\left(269^{\circ} \mathrm{F}\right)$ for 1 hour (gravity displacement sterilizer). Resistance to heat may vary with the specific prion, the degree of contamination and type of sample. Tissue films containing prions are more difficult to decontaminate by steam after they have dried, and human guidelines for surgical instruments recommend that, after use, they be kept moist or wet until decontamination is performed. The cleaning agent used before autoclaving should also be chosen with care, as certain agents (e.g., some enzymatic treatments) can increase the resistance of prions to steam sterilization. Dry heat is less effective than moist heat; some prions can survive dry heat at temperatures as high as $360^{\circ} \mathrm{C}\left(680^{\circ} \mathrm{F}\right)$ for an hour, and one group even reported that infectivity survived incineration at $600^{\circ} \mathrm{C}\left(1112^{\circ} \mathrm{F}\right)$. A combination of chemical and physical decontamination can be more effective than either procedure alone, and effective combinations of chemical agents (e.g., $\mathrm{NaOH}$ ) and autoclaving have been published. It should be noted that even the harshest combination of chemical and physical disinfection is not guaranteed to destroy all prions in all types of samples.

Anecdotal evidence and a recent study on scrapie suggest that decontaminating contaminated facilities, especially sites such as animal pens, may be very difficult. In the latter report, sheep became infected with scrapie prions after being placed in pens that had been pressure washed and decontaminated with high concentrations of sodium hypochlorite $(20,000 \mathrm{ppm}$ free chorine solution) for one hour, followed by painting and full re-galvanization or replacement of metalwork. Decontaminating soil is currently impractical, although some agents, including an aqueous subtilisin-based enzymatic treatment (effective at ambient temperatures), appear promising in the laboratory. Incineration is commonly used for carcasses, but two studies found that composting may reduce or eliminate CWD and other prions in tissues, while another suggested that soil microorganisms might degrade prions in buried carcasses.

\section{Incubation Period}

The minimum incubation period is thought to be approximately 16 months, and the average incubation period is probably 2 to 4 years. The peak incidence occurs between the ages of 2 and 7 years. Much longer incubation periods may also be possible; in herds where CWD is endemic, cases have been reported in animals that were more than 15 years old.

\section{Clinical Signs}

Chronic wasting disease is always fatal. A few apparently asymptomatic animals, or animals with mild clinical signs (e.g., mild ataxia, weight loss), may die suddenly after handling. Such atypical presentations have been reported to be more common in certain populations, such as mule deer with a particular genotype. More typically, cervids develop progressive weight loss, lassitude and behavioral changes over several weeks to months, with many animals becoming severely emaciated before they die. Ataxia, head tremors, teeth grinding, repetitive walking of the enclosure's perimeter, hyperexcitability when handled, or other neurologic signs may be seen; however, neurologic signs and behavioral changes are sometimes subtle, particularly early in the course of the disease or in species such as elk. Some affected animals carry their head low and have a fixed gaze, particularly in the late stages of disease; this can alternate with more normal alertness. Some animals also have difficulty swallowing, leading to excessive salivation. Animals may develop esophageal dilation and regurgitation, or aspiration pneumonia leading to death. Polydipsia/ polyuria and syncope may occur late in the disease. Pruritus has not been reported in affected cervids; however, the coat may be rough and dry, with patchy retention of the winter coat in summer. Reproductive losses, including stillbirths and the death of offspring soon after birth, have been reported in experimentally infected muntjac deer. Most animals with clinical signs die within a few months, although a few may live for up to a year or more. Occasionally, the disease may last only a few days, particularly in elk.

\section{Species other than cervids}

Chronic weight loss, including severe wasting, was the most prominent sign in experimentally infected squirrel monkeys, although muscle tremors, excessive salivation and mild ataxia occurred during the terminal stages in a few animals. Sheep and goats inoculated intracerebrally developed clinical signs that resembled scrapie rather than CWD.

\section{Post Mortem Lesions tif Click to view images}

The gross lesions are nonspecific. The carcass is often emaciated in the later stages, and the hair coat may be rough and dry, with patchy retention of the winter coat in summer. Megaesophagus and aspiration bronchopneumonia are seen in some animals. The rumen contents are often 


\section{Chronic Wasting Disease}

watery, and may be frothy or contain increased amounts of sand and gravel. Abomasal or omasal ulcers may be found. The urine is often dilute in animals that had access to water, but some wild cervids are dehydrated. Some carcasses can be in good condition, with few or no gross lesions, particularly in the early stages of the disease.

The characteristic histopathological lesions are confined to the central nervous system (CNS). In CWD, microscopic changes are most prominent in the diencephalon, olfactory cortex and nuclei of the medulla oblongata (particularly at the level of the obex), but milder changes can be found in other areas of the brain and spinal cord. Neuronal vacuolation and non-inflammatory spongiform changes in the gray matter are pathognomonic. Astrocytosis may be seen. Amyloid plaques are fairly common in deer, but immunohistochemical staining is necessary to demonstrate the presence of amyloid in elk. Lesions are usually bilaterally symmetrical.

\section{Diagnostic Tests}

Histological examination of the brain can be very helpful in diagnosis, but some animals in the early stages of CWD have few or no spongiform changes. This disease is usually confirmed by detecting prions in the CNS and/or the lymphoid tissues, especially the retropharyngeal lymph node, at necropsy. Prions can be found in the lymphoid tissues of most deer, even in some cases where they are not yet detectable in the brain; however, lymphoid samples are less sensitive in elk, and if used alone, can miss some infected animals. In the brain, the optimal site for diagnosis is the medulla oblongata at the level of the obex. Prions can be found in areas of the brain that do not have spongiform changes. In live animals, chronic wasting disease can be diagnosed with palatine tonsil (deer) or rectal lymphoid biopsies (deer and elk). Rectal lymphoid biopsies could also identify some experimentally infected reindeer. The sensitivity of these tests differs with the animal's species, genotype and the stage of the disease, and false negatives are possible. Rectal mucosa biopsies can be taken without sedation, using only topical anesthesia and restraint. Palatine tonsil biopsies require anesthesia.

Immunohistochemistry is considered to be the "gold standard" for diagnosis of CWD. Immunoblotting (Western blotting) and rapid tests including enzyme-linked immunosorbent assays (ELISAs) and a rapid antigendetection strip test can also be used to screen cervids. Some genetically resistant mule deer with subtle clinical signs were found to have histopathological lesions typical of CWD, but only small numbers of prions, negative or equivocal results in immunohistochemistry, and variable ELISA results. In autolyzed brains, CWD may sometimes be confirmed by finding characteristic prion fibrils called scrapie-associated fibrils (SAF) with electron microscopy; however, this test has low sensitivity.

Highly sensitive assays, currently available mainly in research laboratories, include protein misfolding cyclic amplification (PMCA) and quaking-induced conversion or real-time quaking-induced conversion. These techniques detect tiny amounts of prions by their ability to convert PrPc (the normal cellular protein) into prions in vitro. They can sometimes find prions in blood, saliva, urine, feces or other samples from subclinically infected animals, as well as cerebrospinal fluid of animals with clinical signs, and are being investigated for possible use as antemortem diagnostic tests. In research, these techniques have sometimes detected low levels of CWD prions in extracranial tissues (e.g., gastrointestinal tract) not normally collected for CWD diagnosis.

Animal inoculation may be used to detect prions in special circumstances, but this technique is lengthy and labor intensive. Serology is not useful for diagnosis, as antibodies are not made against the CWD agent.

\section{Treatment}

There is no treatment for chronic wasting disease.

\section{Control}

\section{Disease reporting}

A quick response is vital for containing outbreaks in disease-free regions. Veterinarians who encounter or suspect chronic wasting disease should follow their national and/or local guidelines for disease reporting.

Although chronic wasting disease is endemic in the U.S., it is a reportable disease in many states. All deaths must be reported in farmed cervid herds participating in the U.S. herd certification program, and samples must be submitted from these animals by a CWD-certified veterinarian or other authorized individual. Some states also have testing requirements for cervids from herds that do not participate in the federal program. Local wildlife management agencies are often responsible for surveillance programs in wild cervids.

\section{Prevention}

The risk of introducing chronic wasting disease can be reduced by maintaining a closed herd or minimizing outside purchases of stock. If replacement animals must be added, they should be from herds known to be negative for this disease. Voluntary and/or mandatory programs to control or manage CWD in farmed cervids have been established in the U.S. and Canada, with eradication from captive populations as the ultimate goal. Control programs are based on the identification of individual animals, fencing, restrictions on herd additions, and CWD testing of cervids that die on the farm or are slaughtered. Further details on these programs are available online at federal websites (see Internet Resources), as well as from individual states and provinces. Whether it would be possible to breed captive cervids with genotypes more resistant to CWD, without increasing the risk of asymptomatic prion shedding (and consequent environmental contamination), is not yet clear. 
When CWD is found in captive cervids, the herd is usually quarantined. Herd and premises plans are developed and, in some cases, the herd is depopulated. Carcasses from CWD-infected animals cannot be used as food for humans or other animals and must be destroyed. Korean authorities have attempted to eradicate CWD by slaughtering all imported deer, as well as indigenous deer that had been in contact with these deer or were born from them.

Controlling CWD is very difficult in wild cervids. Some states have banned practices that encourage cervids to congregate in certain areas (e.g., feeding or baiting), in an attempt to decrease transmission rates between animals in close contact. Some states have also culled their herds to reduce population density and decrease the spread of disease. Evidence for the effectiveness of such culling programs varies, although some studies suggest that they have been beneficial in some cases. Culling programs might be able to eradicate CWD from a limited area if it was introduced recently. Infected captive cervids should be kept from contact with wild cervids. Many states and provinces also have restrictions on the transportation of tissues from hunter-killed cervids in CWD endemic areas. These guidelines are available at the Chronic Wasting Disease Alliance website (see Internet Resources), state websites and other sources.

\section{Morbidity and Mortality}

Most cases of CWD in captive cervids occur between the ages of 2 and 7 years. An animal's genotype can influence factors such as its susceptibility to infection, the length of the incubation period and/ or the progression of clinical signs, but no cervid genotype appears to be completely resistant to this disease. In newly infected herds of farmed cervids, the prevalence of CWD may be less than $1 \%$. However, once the disease has become established, $50 \%$ or more of the herd often becomes infected. In some cases, the incidence may be as high as $100 \%$. Despite the high infection rate, only one to a few animals generally show signs of disease at a time. Chronic wasting disease is always fatal once an animal becomes symptomatic.

In North America, the prevalence of CWD in wild cervids is reported to be $<5 \%$ in deer and $<2.5 \%$ in elk in many affected areas. However, it differs between regions, and can be higher (e.g., $<15 \%$ of deer in parts of Colorado and Wisconsin). In a few localized "hot spots," CWD has been detected in up to $10-12 \%$ of elk and up to $50 \%$ of wild deer. Highly sensitive prion detection techniques suggest that some of these numbers might be even higher. The vast majority of cases found during the surveillance of wild deer and elk are subclinical. Moose tend to be solitary, which probably reduces the risk of transmission, and very few infected moose have been reported (less than a dozen cases in North America and Europe, as of 2016).

\section{Chronic Wasting Disease}

\section{Public Health}

The emergence of variant Creutzfeldt Jakob disease in humans infected with the BSE prion has raised concerns about the zoonotic potential of other TSEs including chronic wasting disease. While there is currently no evidence to indicate people are susceptible to CWD, the possibility cannot be ruled out at this time. Lymphoid tissues and CNS are the most likely sources of exposure, but CWD prions have also been found in meat, fat, various other tissues and blood of cervids, and no tissues from CWD infected cervids should be considered 'safe.'

Hunters should check with their state wildlife agencies for current precautions and information on endemic areas. Hunters should consider having carcasses tested for CWD; information on this program is available from most state wildlife agencies. Meat from cervids that appear to be ill, as well as meat from apparently healthy animals that test positive for CWD, should not be eaten or fed to any animals. Gloves should be worn when field-dressing a carcass. Boning-out the meat and minimizing the handling of the brain, spinal cord and lymphoid tissues associated with the gastrointestinal tract (e.g. tonsils) may reduce the risk of exposure, but will not necessarily remove all prions. It may be prudent to avoid eating any tissues from untested cervids in endemic areas.

Veterinarians and laboratory workers should take standard precautions when conducting necropsies on CWDsuspects or handling tissues; BSL-2 is the recommended level of protection. Standard precautions include the use of protective clothing and the avoidance of penetrating injuries, contamination of abraded skin, and ingestion. A negative pressure laminar flow hood may be considered for some tissue manipulations. Because prions may be able to survive in the environment for years and are difficult to disinfect, precautions should be taken to avoid contamination of surfaces and equipment. Disposable plastic-coated paper sheets can be used to protect tables and other surfaces. Disposable instruments and work clothing can also be used. No vaccine is available.

\section{Internet Resources}

Canadian Food Inspection Agency. Chronic Wasting Disease (CWD) of Deer and Elk (including information on the herd certification program)

http://www.inspection.gc.ca/animals/terrestrialanimals/diseases/reportable/cwd/eng/1330143462380/1330 $\underline{143991594}$

Centers for Disease Control and Prevention (CDC). Chronic Wasting Disease http://www.cdc.gov/prions/cwd/index.html

Chronic Wasting Disease Alliance (CWDA) http://www.cwd-info.org/ 
European Food Safety Authority. Transmissible

Spongiform Encephalopathies

https://www.efsa.europa.eu/en/topics/topic/transmissiblespo ngiformencephalopathies

Norwegian Food Safety Authority (cases in Norway) http://www.mattilsynet.no/language/english/animals/

U.S. Geological Survey (USGS). Chronic Wasting Disease http://www.nwhc.usgs.gov/disease information/chronic_wa sting disease/index.jsp

U.S. Department of Agriculture. Chronic Wasting Disease (including information on the CWD Certified and Monitored Herd Programs).

https://www.aphis.usda.gov/aphis/ourfocus/animalhealth/an imal-disease-

information/sa_alternate_livestock/sa_cervid_health/sa_cw d/ct_cwd_index

\section{Acknowledgements}

This factsheet was written by Anna Rovid Spickler, DVM, $\mathrm{PhD}$, Veterinary Specialist from the Center for Food Security and Public Health. The U.S. Department of Agriculture Animal and Plant Health Inspection Service (USDA APHIS) provided funding for this factsheet through a series of cooperative agreements related to the development of resources for initial accreditation training.

The following format can be used to cite this factsheet. Spickler, Anna Rovid. 2016. Chronic Wasting Disease. Retrieved from http://www.cfsph.iastate.edu/DiseaseInfo/ factsheets.php.

\section{References}

Acquatella-Tran Van Ba I, Imberdis T, Perrier V. From prion diseases to prion-like propagation mechanisms of neurodegenerative diseases. Int J Cell Biol. 2013;2013:975832.

Aguzzi A, Heikenwalder M, Miele G. Progress and problems in the biology, diagnostics, and therapeutics of prion diseases. $\mathrm{J}$ Clin Invest. 2004;114:153-60.

Anderson CA, Bosque P, Filley CM, Arciniegas DB, Kleinschmidt-Demasters BK, Pape WJ, Tyler KL. Colorado surveillance program for chronic wasting disease transmission to humans: lessons from 2 highly suspicious but negative cases. Arch Neurol. 2007;64:439-41.

Angers RC, Browning SR, Seward TS, Sigurdson CJ, Miller MW, Hoover EA, Telling GC. Prions in skeletal muscles of deer with chronic wasting disease. Science. 2006;311:1117.

Angers RC, Seward TS, Napier D, Green M, Hoover E, Spraker T, O'Rourke K, Balachandran A, Telling GC. Chronic wasting disease prions in elk antler velvet. Emerg Infect Dis. 2009;15(5):696-703.

Baeten LA, Powers BE, Jewell JE, Spraker TR, Miller MW. A natural case of chronic wasting disease in a free-ranging moose (Alces alces shirasi). J Wildl Dis. 2007;43:309-14.

\section{Chronic Wasting Disease}

Balachandran A, Harrington NP, Algire J, Soutyrine A, Spraker TR, Jeffrey M, González L, O'Rourke KI. Experimental oral transmission of chronic wasting disease to red deer (Cervus elaphus elaphus): early detection and late stage distribution of protease-resistant prion protein. Can Vet J. 2010;51(2):169-78.

Barria MA, Ironside JW, Head MW. Exploring the zoonotic potential of animal prion diseases: in vivo and in vitro approaches. Prion. 2014;8(1):85-91.

Belay ED, Maddox RA, Williams ES, Miller MW, Gambetti P, Schonberger LB. Chronic wasting disease and potential transmission to humans. Emerg Infect Dis. 2004;10:977-84.

Brandt AL, Kelly AC, Green ML, Shelton P, Novakofski J, Mateus-Pinilla NE. Prion protein gene sequence and chronic wasting disease susceptibility in white-tailed deer (Odocoileus virginianus). Prion. 2015;9(6):449-62.

Brown P, Abee CR. Working with transmissible spongiform encephalopathy agents. ILAR J. 2005;46:44-52.

Brown P, Rau EH, Johnson BK, Bacote AE, Gibbs CJ, Jr., Gajdusek DC. New studies on the heat resistance of hamsteradapted scrapie agent: threshold survival after ashing at 600 degrees $C$ suggests an inorganic template of replication. Proc Natl Acad Sci USA. 2000;97:3418-21.

Centers for Disease Control and Prevention (CDC). Chronic wasting disease [online]. CDC; 2007 Jan. Available at: http://www.cdc.gov/ncidod/dvrd/cwd/.* Accessed 19 Sept. 2008.

Chang B, Cheng X, Yin S, Pan T, Zhang H, Wong P, Kang SC, Xiao F, Yan H, Li C, Wolfe LL, Miller MW, Wisniewski T, Greene MI, Sy MS. Test for detection of disease-associated prion aggregate in the blood of infected but asymptomatic animals. Clin Vaccine Immunol. 2007;14:36-43.

Chesney AR, Booth CJ, Lietz CB, Li L, Pedersen JA. Peroxymonosulfate rapidly inactivates the disease-associated prion protein. Environ Sci Technol. 2016;50(13):7095-105.

Chronic Wasting Disease Alliance. Carcass transportation regulations in the United States and Canada [online]. Available at: http://www.cwd-info.org/index.php/ fuseaction/policy.main.* Accessed 19 Sept 2008.

Chronic Wasting Disease Alliance. Chronic wasting disease (CWD) outbreaks and surveillance program in the Republic of Korea. 2011. Available at: http://cwd-info.org/chronicwasting-disease-cwd-outbreaks-and-surveillance-program-inthe-republic-of-korea/. Accessed 28 July 2016.

Chronic Wasting Disease Alliance. The first detection of chronic wasting disease (CWD) in Europe. 2016. Available at: http://cwd-info.org/the-first-detection-of-chronic-wastingdisease-cwd-in-europe/. Accessed 29 Jul 2016.

Colorado Division of Wildlife. Chronic wasting disease in Colorado, 2006-2008. Colorado Division of Wildlife Report. Fort Collins, Colorado; 2009. 5 p.

Daus ML, Breyer J, Wagenfuehr K, Wemheuer WM, Thomzig A, Schulz-Schaeffer WJ, Beekes M. presence and seeding activity of pathological prion protein $(\operatorname{PrP}(\mathrm{TSE}))$ in skeletal muscles of white-tailed deer infected with chronic wasting disease. PLoS One. 2011;6(4):e18345.

Elder AM, Henderson DM, Nalls AV, Wilham JM, Caughey BW, Hoover EA, Kincaid AE, Bartz JC, Mathiason CK. In vitro detection of prionemia in TSE-infected cervids and hamsters. PLoS One. 2013;8(11):e80203. 
Fichet G, Comoy E, Dehen C, Challier L, Antloga K, Deslys JP, McDonnell G. Investigations of a prion infectivity assay to evaluate methods of decontamination. J Microbiol Methods. 2007;70:511-8.

Fichet G, Comoy E, Duval C, Antloga K, Dehen C, Charbonnier A, McDonnell G, Brown P, Lasmézas CI, Deslys JP. Novel methods for disinfection of prion-contaminated medical devices. Lancet. 2004;364:521-6.

Fischer JR, Nettles VF (College of Veterinary Medicine, The University of Georgia). National chronic wasting disease surveillance in free-ranging cervids: accomplishments and needs [online]. In: USAHA 2002 Proceedings; 2002 Oct 2023; St. Louis, MO. Available at: http://www.usaha.org/speeches/speech02/s02cwdss.html.* Accessed 2 Dec 2003.

Gavier-Widén D, Stack MJ, Baron T, Balachandran A, Simmons M. Diagnosis of transmissible spongiform encephalopathies in animals: a review. J Vet Diagn Invest. 2005;17:509-27.

Gilch S. Overview of chronic wasting disease. In: Kahn CM, Line S, Aiello SE, editors.. The Merck veterinary manual [online]. Whitehouse Station, NJ: Merck and Co; 2013. Available at: http://www.merckvetmanual.com/mvm/nervous_system/chron ic_wasting_disease/overview_of_chronic_wasting_disease.ht ml. Accessed 25 Jul 2016.

Gilch S. Overview of chronic wasting disease. In: Kahn CM, Line S, Aiello SE, editors.. The Merck veterinary manual [online]. Whitehouse Station, NJ: Merck and Co; 2013. Available at: http://www.merckvetmanual.com/mvm/nervous_system/chron ic_wasting_disease/overview_of_chronic_wasting_disease.ht ml. Accessed 20 Jul 2016.

Gilch S, Chitoor N, Taguchi Y, Stuart M, Jewell JE, Schätzl HM.Chronic wasting disease. Top Curr Chem. 2011;305:51-77.

Goldmann W. PrP genetics in ruminant transmissible spongiform encephalopathies. Vet Res. 2008;39:30.

Gould DH, Voss JL, Miller MW, Bachand AM, Cummings BA, Frank AA. Survey of cattle in northeast Colorado for evidence of chronic wasting disease: geographical and high-risk targeted sample. J Vet Diagn Invest. 2003;15:274-7.

Greenlee JJ, Nicholson EM, Smith JD, Kunkle RA, Hamir AN. Susceptibility of cattle to the agent of chronic wasting disease from elk after intracranial inoculation. J Vet Diagn Invest. 2012;24(6):1087-93.

Haley NJ, Hoover EA. Chronic wasting disease of cervids: current knowledge and future perspectives. Annu Rev Anim Biosci. 2015;3:305-25.

Haley NJ, Mathiason CK, Carver S, Zabel M, Telling GC, Hoover EA.Detection of chronic wasting disease prions in salivary, urinary, and intestinal tissues of deer: potential mechanisms of prion shedding and transmission. J Virol. 2011;85(13):6309-18.

Haley NJ, Mathiason CK, Zabel MD, Telling GC, Hoover EA. Detection of sub-clinical CWD infection in conventional testnegative deer long after oral exposure to urine and feces from CWD+ deer. PLoS One. 2009;4(11):e7990.

Haley NJ, Seelig DM, Zabel MD, Telling GC, Hoover EA. Detection of CWD prions in urine and saliva of deer by transgenic mouse bioassay. PLoS One. 2009;4(3):e4848.

Haley NJ, Van de Motter a, Carver S, Henderson D, Davenport K, Seelig DM, Mathiason C, Hoover E. Prion-seeding activity in cerebrospinal fluid of deer with chronic wasting disease. PLoS One. 2013;8(11):e81488.

\section{Chronic Wasting Disease}

Hamir AN, Greenlee JJ, Nicholson EM, Kunkle RA, Richt JA, Miller JM, Hall M. Experimental transmission of chronic wasting disease (CWD) from elk and white-tailed deer to fallow deer by intracerebral route: final report. Can J Vet Res. 2011;75(2):152-6.

Hamir AN, Kehrli ME Jr, Kunkle RA, Greenlee JJ, Nicholson EM, Richt JA, Miller JM, Cutlip RC. Experimental interspecies transmission studies of the transmissible spongiform encephalopathies to cattle: comparison to bovine spongiform encephalopathy in cattle. J Vet Diagn Invest. 2011;23(3):407-20.

Hamir AN, Kunkle RA, Miller JM, Cutlip RC, Richt JA, Kehrli ME Jr, Williams ES. Age-related lesions in laboratoryconfined raccoons (Procyon lotor) inoculated with the agent of chronic wasting disease of mule deer. J Vet Diagn Invest. 2007;19(6):680-6.

Hamir AN, Kunkle RA, Nicholson EM, Miller JM, Hall SM, Schoenenbruecher H, Brunelle BW, Richt JA. Preliminary observations on the experimental transmission of chronic wasting disease (CWD) from elk and white-tailed deer to fallow deer. J Comp Pathol. 2008;138(2-3):121-30.

Hamir AN, Miller JM,Cutlip RC, Stack MJ,Chaplin MJ, Jenny AL, Williams ES. Experimental inoculation of scrapie and chronic wasting disease agents in raccoons (Procyon lotor). Vet Rec. 2003;153:121-3.

Happ GM, Huson HJ, Beckmen KB, Kennedy LJ Prion protein genes in caribou from Alaska. J Wildl Dis. 2007;43:224-8.

Harrington RD, Baszler TV, O'Rourke KI, Schneider DA, Spraker TR, Liggitt HD, Knowles DP. A species barrier limits transmission of chronic wasting disease to mink (Mustela vison). J Gen Virol. 2008;89(Pt 4):1086-96.

Hawkins SA, Simmons HA, Gough KC, Maddison BC. Persistence of ovine scrapie infectivity in a farm environment following cleaning and decontamination. Vet Rec. 2015;176(4):99.

Heisey DM, Mickelsen NA, Schneider JR, Johnson CJ, Johnson CJ, Langenberg JA, Bochsler PN, Keane DP, Barr DJ. Chronic wasting disease (CWD) susceptibility of several North American rodents that are sympatric with cervid CWD epidemics. J Virol. 2010;84(1):210-5.

Henderson DM, Davenport KA, Haley NJ, Denkers ND, Mathiason CK, Hoover EA. Quantitative assessment of prion infectivity in tissues and body fluids by real-time quakinginduced conversion. J Gen Virol. 2015;96(Pt 1):210-9.

Henderson DM, Denkers ND, Hoover CE, Garbino N, Mathiason CK, Hoover EA. Longitudinal detection of prion shedding in saliva and urine by chronic wasting disease-infected deer by real-time quaking-induced conversion. J Virol. 2015;89(18):9338-47.

Henderson DM, Manca M, Haley NJ, Denkers ND, Nalls AV, Mathiason CK, Caughey B, Hoover EA. Rapid antemortem detection of CWD prions in deer saliva. PLoS One. 2013;8(9):e74377.

Jacques CN, Jenks JA, Jenny AL, Griffin SL. Prevalence of chronic wasting disease and bovine tuberculosis in freeranging deer and elk in South Dakota. J Wildl Dis. 2003;39:29-34. 
Jennelle CS, Samuel MD, Nolden CA, Keane DP, Barr DJ, Johnson C, Vanderloo JP, Aiken JM, Hamir AN, Hoover EA. Surveillance for transmissible spongiform encephalopathy in scavengers of white-tailed deer carcasses in the chronic wasting disease area of Wisconsin. J Toxicol Environ Health A. 2009;72(17-18):1018-24.

Jewell JE, Brown J, Kreeger T, Williams ES. Prion protein in cardiac muscle of elk (Cervus elaphus nelsoni) and whitetailed deer (Odocoileus virginianus) infected with chronic wasting disease. J Gen Virol. 2006;87:3443-50.

Keane D, Barr D, Osborn R, Langenberg J, O'Rourke K, Schneider D, Bochsler P.Validation of use of rectoanal mucosa-associated lymphoid tissue for immunohistochemical diagnosis of chronic wasting disease in white-tailed deer (Odocoileus virginianus). $\mathrm{J}$ Clin Microbiol. 2009;47(5):1412-7.

Kim TY, Shon HJ, Joo YS, Mun UK, Kang KS, Lee YS. Additional cases of chronic wasting disease in imported deer in Korea. J Vet Med Sci. 2005;67:753-9.

Kong Q, Huang S, Zou W, Vanegas D, Wang M, Wu D, Yuan J, Zheng M, Bai H, Deng H, Chen K, Jenny AL, O'Rourke K, Belay ED, Schonberger LB, Petersen RB, Sy MS, Chen SG, Gambetti P. Chronic wasting disease of elk: transmissibility to humans examined by transgenic mouse models. J Neurosci. 2005;25:7944-9.

Kreeger T. Distribution and status of chronic wasting disease in Wyoming [abstract]. In: National chronic wasting disease symposium [online]. 2002 Aug 6-7; Denver, CO. Available at: http://www.cwdinfo.org/index.php/fuseaction/resources.symposiumAbstracts/ \#23.* Accessed 22 Nov 2003.

Kreeger TJ, Montgomery DL, Jewell JE, Schultz W, Williams ES. Oral transmission of chronic wasting disease in captive Shira's moose. J Wildl Dis. 2006;42:640-5.

Kurt TD, Sigurdson CJ. Cross-species transmission of CWD prions. Prion. 2016;10(1):83-91.

Lee YH, Sohn HJ, Kim MJ, Kim HJ, Park KJ, Lee WY, Yun EI, Tark DS, Choi YP, Cho IS, Balachandran A. Experimental chronic wasting disease in wild type VM mice. J Vet Med Sci. 2013;75(8):1107-10

Maddison BC, Owen JP, Bishop K, Shaw G, Rees HC, Gough $\mathrm{KC}$. The interaction of ruminant $\operatorname{PrP}(\mathrm{Sc})$ with soils is influenced by prion source and soil type. Environ Sci Technol. 2010;44(22):8503-8

Manjerovic MB, Green ML, Mateus-Pinilla N, Novakofski J. The importance of localized culling in stabilizing chronic wasting disease prevalence in white-tailed deer populations. Prev Vet Med. 2014;113(1):139-45.

Marsh RF, Kincaid AE, Bessen RA, Bartz JC. Interspecies transmission of chronic wasting disease prions to squirrel monkeys (Saimiri sciureus). J Virol. 2005;79:13794-6.

Martin S, Jeffrey M, González L, Sisó S, Reid HW, Steele P, Dagleish MP, Stack MJ, Chaplin MJ, Balachandran A. Immunohistochemical and biochemical characteristics of BSE and CWD in experimentally infected European red deer (Cervus elaphus elaphus). BMC Vet Res. 2009;5:26.

Mathiason CK, Hays SA, Powers J, Hayes-Klug J, Langenberg J, Dahmes SJ, Osborn DA, Miller KV, Warren RJ, Mason GL, Hoover EA. Infectious prions in pre-clinical deer and transmission of chronic wasting disease solely by environmental exposure. PLoS One. 2009;4(6):e5916.

\section{Chronic Wasting Disease}

Mathiason CK, Powers JG, Dahmes SJ, Osborn DA, Miller KV, Warren RJ, Mason GL, Hays SA, Hayes-Klug J, Seelig DM, Wild MA, Wolfe LL, Spraker TR, Miller MW, Sigurdson CJ, Telling GC, Hoover EA. Infectious prions in the saliva and blood of deer with chronic wasting disease. Science. 2006;314:133-6.

Matsuura Y, Ishikawa Y, Bo X, Murayama Y, Yokoyama T, Somerville RA, Kitamoto T, Mohri S. Quantitative analysis of wet-heat inactivation in bovine spongiform encephalopathy. Biochem Biophys Res Commun. 2013;432(1):86-91.

McDonnell G, Dehen C, Perrin A, Thomas V, Igel-Egalon A, Burke PA, Deslys JP, Comoy E. Cleaning, disinfection and sterilization of surface prion contamination. J Hosp Infect. 2013;85(4):268-73.

Miller MW, Wild MA. Epidemiology of chronic wasting disease in captive white-tailed and mule deer. J Wildl Dis. 2004;40:320-7.

Miller MW, Williams ES, Hobbs NT, Wolfe LL. Environmental sources of prion transmission in mule deer. Emerg Infect Dis. 2004;10:1003-6

Mitchell GB, Sigurdson CJ, O'Rourke KI, Algire J, Harrington NP, Walther I, Spraker TR, Balachandran A. Experimental oral transmission of chronic wasting disease to reindeer (Rangifer tarandus tarandus). PLoS One. 2012;7(6):e39055.

Monello RJ, Powers JG, Hobbs NT, Spraker TR, O'Rourke KI, Wild MA. Efficacy of antemortem rectal biopsies to diagnose and estimate prevalence of chronic wasting disease in freeranging cow elk (Cervus elaphus nelsoni). Wildl Dis. 2013 Apr;49(2):270-8. doi: 10.7589/2011-12-362.

Nalls AV, McNulty E, Powers J, Seelig DM, Hoover C, Haley NJ, Hayes-Klug J, Anderson K, Stewart P, Goldmann W, Hoover EA, Mathiason CK. Mother to offspring transmission of chronic wasting disease in reeves' muntjac deer. PLoS One. 2013;8(8):e71844.

Nichols TA, Fischer JW, Spraker TR, Kong Q, VerCauteren KC. CWD prions remain infectious after passage through the digestive system of coyotes (Canis latrans). Prion. 2015;9(5):367-75.

Nichols TA, Pulford B, Wyckoff AC, Meyerett C, Michel B, Gertig K, Hoover EA, Jewell JE, Telling GC, Zabel MD. Detection of protease-resistant cervid prion protein in water from a CWD-endemic area. Prion. 2009;3(3):171-83.

Nichols TA, Spraker TR, Gidlewski T, Powers JG, Telling GC, VerCauteren KC, Zabel MD. Detection of prion protein in the cerebrospinal fluid of elk (Cervus canadensis nelsoni) with chronic wasting disease using protein misfolding cyclic amplification. J Vet Diagn Invest. 2012;24(4):746-9.

Nichols TA, Spraker TR, Rigg TD, Meyerett-Reid C, Hoover C, Michel B, Bian J, Hoover E, Gidlewski T, Balachandran A, O'Rourke K, Telling GC, Bowen R, Zabel MD, VerCauteren $\mathrm{KC}$. Intranasal inoculation of white-tailed deer (Odocoileus virginianus) with lyophilized chronic wasting disease prion particulate complexed to montmorillonite clay. PLoS One. 2013;8(5):e62455.

Norwegian Food Safety Authority. Chronic wasting disease in Norway. 2016. Available at: http://www.mattilsynet.no/language/english/animals/chronic wasting_disease_in_norway.23274. Accessed 28 Jul 2016. 
Olszowy KM, Lavelle J, Rachfal K, Hempstead S, Drouin K, Darcy JM 2nd, Reiber C, Garruto RM. Six-year follow-up of a point-source exposure to CWD contaminated venison in an Upstate New York community: risk behaviours and health outcomes 2005-2011. Public Health. 2014;128(9):860-8.

Promed Mail. Chronic wasting disease, elk - South Korea (Kyungsang). Nov 25, 2004. Archive Number 20041125.3155. Available at: http://www.promedmail.org. Accessed 30 Sept 2008.

Promed Mail. Chronic wasting disease, cervid - Europe (02): (Norway) moose. Archive Number: 20160614.4276448 Available at: http://www.promedmail.org. Accessed 28 Jul 2016.

Pulford B, Spraker TR, Wyckoff AC, Meyerett C, Bender H, Ferguson A, Wyatt B, Lockwood K, Powers J, Telling GC, Wild MA, Zabel MD. Detection of PrPCWD in feces from naturally exposed Rocky Mountain elk (Cervus elaphus nelsoni) using protein misfolding cyclic amplification. J Wildl Dis. 2012;48(2):425-34.

Race B, Meade-White KD, Miller MW, Barbian KD, Rubenstein $\mathrm{R}$, et al. Susceptibilities of nonhuman primates to chronic wasting disease. Emerg Infect Dis. 2009;15(9):1366-76.

Race B, Meade-White KD, Phillips K, Striebel J, Race R, Chesebro B. Chronic wasting disease agents in nonhuman primates. Emerg Infect Dis. 2014;20(5):833-7.

Race B, Meade-White K, Race R, Chesebro B. Prion infectivity in fat of deer with chronic wasting disease. J Virol. 2009;83(18):9608-10.

Race BL, Meade-White KD, Ward A, Jewell J, Miller MW, Williams ES, Chesebro B, Race RE. Levels of abnormal prion protein in deer and elk with chronic wasting disease. Emerg Infect Dis. 2007;13:824-30.

Raymond GJ, Raymond LD, Meade-White KD, Hughson AG, Favara C, Gardner D, Williams ES, Miller MW, Race RE, Caughey B. Transmission and adaptation of chronic wasting disease to hamsters and transgenic mice: evidence for strains. J Virol. 2007;81:4305-14.

Rhyan JC, Miller MW, Spraker TR, McCollum M, Nol P, Wolfe LL, Davis TR, Creekmore L, O'Rourke KI. Failure of fallow deer (Dama dama) to develop chronic wasting disease when exposed to a contaminated environment and infected mule deer (Odocoileus hemionus). J Wildl Dis. 2011;47(3):739-44.

Robinson SJ, Samuel MD, O'Rourke KI, Johnson CJ. The role of genetics in chronic wasting disease of North American cervids. Prion. 2012;6(2):153-62.

Rogez-Kreuz C, Yousfi R, Soufflet C, Quadrio I, Yan ZX, Huyot V, Aubenque C, Destrez P, Roth K, Roberts C, Favero M, Clayette $\mathrm{P}$. Inactivation of animal and human prions by hydrogen peroxide gas plasma sterilization. Infect Control Hosp Epidemiol. 2009;30(8):769-77.

Rubenstein R, Chang B, Gray P, Piltch M, Bulgin MS, SorensenMelson S, Miller MW. Prion disease detection, PMCA kinetics, and $\mathrm{IgG}$ in urine from sheep naturally/experimentally infected with scrapie and deer with preclinical/clinical chronic wasting disease. J Virol. 2011;85(17):9031-8.

Rutala WA, Weber DJ; Society for Healthcare Epidemiology of America. Guideline for disinfection and sterilization of prioncontaminated medical instruments. Infect Control Hosp Epidemiol. 2010;31(2):107-17.

Saunders SE, Bartelt-Hunt SL, Bartz JC. Occurrence, transmission, and zoonotic potential of chronic wasting disease. Emerg Infect Dis. 2012;18(3):369-76.

\section{Chronic Wasting Disease}

Saunders SE, Bartz JC, Telling GC, Bartelt-Hunt SL. Environmentally-relevant forms of the prion protein. Environ Sci Technol. 2008;42(17):6573-9.

Saunders SE, Bartz JC, Vercauteren KC, Bartelt-Hunt SL. An enzymatic treatment of soil-bound prions effectively inhibits replication. Appl Environ Microbiol. 2011;77(13):4313-7.

Schuler KL, Jenks JA, DePerno CS, Wild MA, Swanson CC. Tonsillar biopsy test for chronic wasting disease: Two sampling approaches in mule deer and white-tailed deer. $\mathbf{J}$ Wildl Dis. 2005;41:820-4.

Schwabenlander MD, Culhane MR, Hall SM, Goyal SM, Anderson PL, Carstensen M, Wells SJ, Slade WB, Armién AG. A case of chronic wasting disease in a captive red deer (Cervus elaphus). J Vet Diagn Invest. 2013;25(5):573-6.

Seelig DM, Nalls AV, Flasik M, Frank V, Eaton S, Mathiason CK, Hoover EA. Lesion profiling and subcellular prion localization of cervid chronic wasting disease in domestic cats. Vet Pathol. 2015;52(1):107-19.

Seidel B, Thomzig A, Buschmann A, Groschup MH, Peters R, Beekes M, Terytze K. Scrapie Agent (Strain 263K) can transmit disease via the oral route after persistence in soil over years. PLoS ONE. 2007;2(5):e435.

Selariu A, Powers JG, Nalls A, Brandhuber M, Mayfield A, Fullaway S, Wyckoff CA, Goldmann W, Zabel MM, Wild MA, Hoover EA, Mathiason CK. In utero transmission and tissue distribution of chronic wasting disease-associated prions in free-ranging Rocky Mountain elk. J Gen Virol. 2015;96(11):3444-55.

Sigurdson CJ, Aguzzi A. Chronic wasting disease. Biochim Biophys Acta. 2007;1772:610-8.

Sigurdson CJ, Mathiason CK, Perrott MR, Eliason GA, Spraker TR, Glatzel M, Manco G, Bartz JC, Miller MW, Hoover EA. Experimental chronic wasting disease (CWD) in the ferret. J Comp Pathol. 2008;138(4):189-96.

Smith CB, Booth CJ, Pedersen JA. Fate of prions in soil: a review. J Environ Qual. 2011;40(2):449-61.

Smith JD, Nicholson EM, Greenlee JJ. Evaluation of a combinatorial approach to prion inactivation using an oxidizing agent, SDS, and proteinase K. BMC Vet Res. 2013;9:151.

Sohn HJ, Kim JH, Choi KS, Nah JJ, Joo YS, Jean YH, Ahn SW, Kim OK, Kim DY, Balachandran A. A case of chronic wasting disease in an elk imported to Korea from Canada. J Vet Med Sci. 2002;64:855-8.

Somerville RA, Gentles N. Characterization of the effect of heat on agent strains of the transmissible spongiform encephalopathies. J Gen Virol. 2011;92(Pt 7):1738-48.

Spraker TR, Gidlewski TL, Balachandran A, VerCauteren KC, Creekmore L, Munger RD. Detection of $\operatorname{PrP}(\mathrm{CWD})$ in postmortem rectal lymphoid tissues in Rocky Mountain elk (Cervus elaphus nelsoni) infected with chronic wasting disease. J Vet Diagn Invest. 2006;18:553-7.

Spraker TR, VerCauteren KC, Gidlewski T, Schneider DA, Munger R, Balachandran A, O'Rourke KI. Antemortem detection of PrPCWD in preclinical, ranch-raised Rocky Mountain elk (Cervus elaphus nelsoni) by biopsy of the rectal mucosa. J Vet Diagn Invest. 2009;21(1):15-24. 
Tamgüney G, Miller MW, Wolfe LL, Sirochman TM, Glidden DV, Palmer C, Lemus A, DeArmond SJ, Prusiner SB.

Asymptomatic deer excrete infectious prions in faeces. Nature. 2009;461(7263):529-32.

Thomsen BV, Schneider DA, O'Rourke KI, Gidlewski T, McLane J, Allen RW, McIsaac AA, Mitchell GB, Keane DP, Spraker TR, Balachandran A. Diagnostic accuracy of rectal mucosa biopsy testing for chronic wasting disease within white-tailed deer (Odocoileus virginianus) herds in North America: effects of age, sex, polymorphism at PRNP codon 96, and disease progression. J Vet Diagn Invest. 2012;24(5):878-87.

U.S. Department of Agriculture, Animal and Plant Health Inspection Service [USDA APHIS]. Transmissible spongiform encephalopathies [online]. USDA APHIS; 2000 July. Available at: http://www.aphis.usda.gov/oa/pubs/fstse.html.* Accessed 7 Nov 2001.

VerCauteren KC, Pilon JL, Nash PB, Phillips GE, Fischer JW. Prion remains infectious after passage through digestive system of American crows (Corvus brachyrhynchos). PLoS One. 2012;7(10):e45774.

Williams ES. Chronic wasting disease. Vet Pathol. 2005;42:530-49.

Wolfe LL, Fox KA, Miller MW. "Atypical" chronic wasting disease in PRNP genotype 225FF mule deer. J Wildl Dis. 2014;50(3):660-5.

Yuan Q, Eckland T, Telling G, Bartz J, Bartelt-Hunt S. Mitigation of prion infectivity and conversion capacity by a simulated natural process--repeated cycles of drying and wetting. PLoS Pathog. 2015 Feb 9;11(2):e1004638.

Xu S, Reuter T, Gilroyed BH, Mitchell GB, Price LM, Dudas S, Braithwaite SL, Graham C, Czub S, Leonard JJ, Balachandran A, Neumann NF, Belosevic M, McAllister TA. Biodegradation of prions in compost. Environ Sci Technol. 2014;48(12):6909-18.

*Link is defunct 